\title{
光-钴协同催化的高区域、高对映选择性醛-炔还原偶联反应
}

\author{
蒋滨阳施世良*
}

(中国科学院上海有机化学研究所 上海 200032)

\section{Highly Regio- and Enantio-selective Reductive Coupling of Alde- hydes and Alkynes via Photoredox Cobalt Dual Catalysis}

\author{
Jiang, Binyang Shi, Shi-Liang*
}

(Shanghai Institute of Organic Chemistry, Chinese Academy of Sciences, Shanghai 200032)

手性烯丙醇是有机合成中的重要合成子以及众多 药物及天然产物中的关键手性骨架，发展其高效的不对 称合成方法是有机合成中的一个重要目标 ${ }^{[1]}$. 利用金属 试剂对羰基化合物进行加成是合成这类化合物的常用 手段 ${ }^{[2-3]}$, 然而这一方法需要预先通过多步制备金属试 剂, 原子经济性和反应效率均有待提升(Scheme 1, a).

过渡金属催化的醛与炔烃的还原偶联反应是合成 手性烯丙醇的强有力的手段 ${ }^{[-5}$, 这类反应常使用金属 铑或者镍作为催化剂, 外加还原剂作为氢源实现醛与炔 烃的不对称还原偶联(Scheme 1, b). 由于避免了具有强 碱性和亲核性的金属试剂的使用, 该类反应具有较好的 官能团耐受性. 然而在这类反应中, 当使用简单的非对 称内炔作为底物时, 实现高效的区域和立体选择性控制 仍是一个亟待解决的挑战 ${ }^{[6]}$.

(a) Metal-catalyzed asymmetric addition to aldehydes

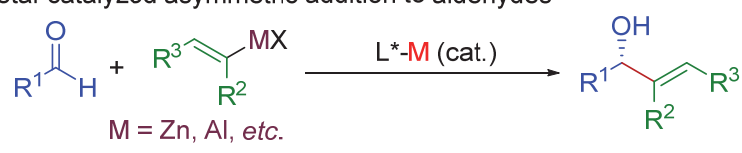

(b) Transition-metal-catalyzed asymmetric reductive coupling

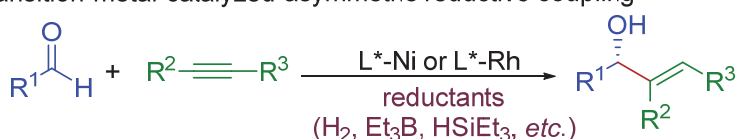

图式 1 由醛制备手性烯丙醇的方法

Scheme 1 Synthesis of chiral allylic alcohols from aldehydes

钴作为一类低毒且丰富易得的金属，在多种类型的 催化反应中有广泛的应用 ${ }^{[7-8]}$, 然而钴催化的还原偶联 反应鲜有报道, 其中钴催化的酫与炔烃的不对称还原偶 联反应一直未能实现.
最近, 中国科学院兰州化学物理研究所夏纪宝课题 组 ${ }^{[9]}$ 发展了光-钴协同催化的醛与炔烃的不对称还原偶 联反应. 在先前的光-镍协同催化 1,3-丁二烯与醛的还 原偶联 ${ }^{[10]}$ 工作的基础上，该团队将光致氧化还原体系 与钴催化体系结合, 实现了以醛与简单甲基内炔为底物 的手性烯丙醇的高效(高达 $93 \%$ 产率)、高对映选择性(高 达 $99 \% e e$ )、高区域选择性(>95: $5 r r$ 和高顺反选择性 $(>95: 5 E / Z)$ 合成(Scheme 2). 该方法具有良好的底物
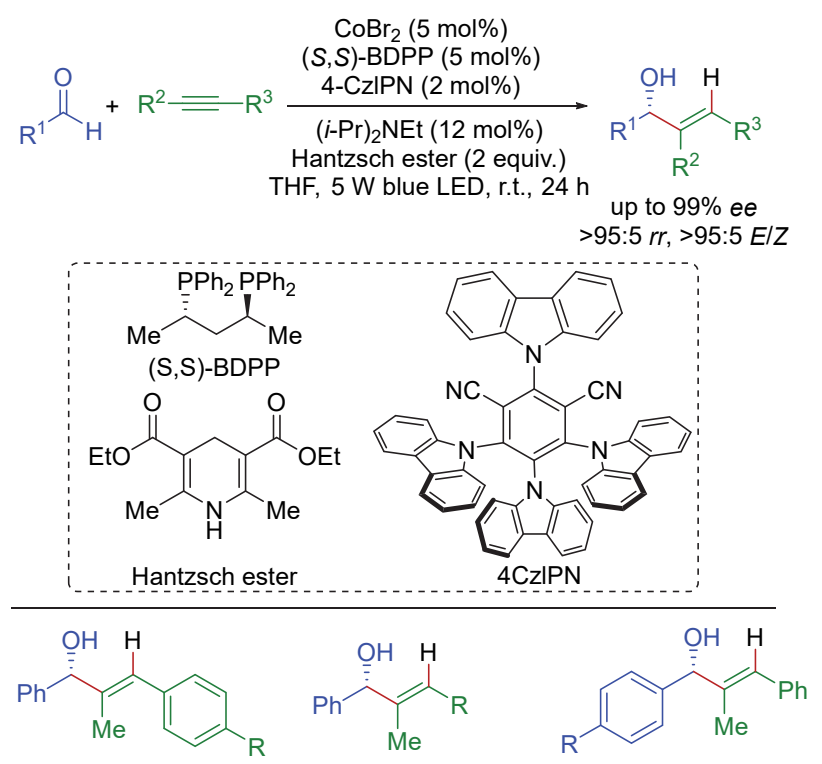

$\mathrm{R}=\mathrm{Me}, 87 \%, 98 \%$ ee $\mathrm{R}=\mathrm{Me}, 75 \%, 99 \%$ ee $\mathrm{R}=\mathrm{Bpin}, 86 \%, 98 \%$ ee $\mathrm{R}=\mathrm{Cl}, 79 \%, 98 \%$ ee $\mathrm{R}=n-\mathrm{Pr}, 43 \%, 98 \%$ ee $\mathrm{R}=\mathrm{CO}_{2} \mathrm{Me}, 93 \%, 93 \%$ ee

图式 2 光-钴协同催化的不对称醛-炔还原偶联

Scheme 2 Regio- and enantioselective reductive coupling of aldehydes and alkynes via photoredox cobalt dual catalysis

* Corresponding author. E-mail: shiliangshi@sioc.ac.cn. Published online July 12, 2021. 
范围( $>42$ 个实例), 可以兼容芳基氟化物、氯化物、醚、 酰胺、酯及硣酸酯等一系列官能团, 同时对于吗啉及噻 吩等杂环化合物也有较好的反应结果. 值得一提的是, 对于区域选择性较难控制的二烷基内炔底物, 反应也能 以大于 $95: 5$ 的区域选择性和大于 $96 \%$ 的对映选择性得 到目标产物. 另外, 反应可以用于手性氨基醇的对映选 择性合成中, 具有良好的应用潜力.

作者也通过一系列实验探究了反应机理. 机理实验 排除了自由基中间体生成的可能, 表明反应可能存在钴 氢物种以及质子中间体. Stern-Volmer 分析表明汉斯酯 与激发态的 $4 \mathrm{CzlPN}$ 之间发生了单电子转移过程, 因而 作者提出了可能的反应机理(Scheme 3): 激发态光敏剂 被汉斯酯淬灭生成的自由基负离子 $\left(4 \mathrm{CzlPN}^{--}\right)$将钴催化 剂还原为一价钴, 随后一价钴与醛和炔烃配位, 进而发
生氧化环化得到氧杂五元环钴中间体 INT1; 这一中间 体随后被质子解开环生成 INT2, INT2 也可能由生成的 钴氢物种对炔烃进行加成，再对醛进行亲核加成得到; 生成的 INT2 中间体最后经过单电子还原和再一次的质 子解得到目标产物. 手性配体的作用使得炔只能从醛的 $R e$ 面进攻，因而该反应具有优秀的对映选择性.

综上所述，夏纪宝团队使用钴作为金属催化剂，将 光致氧化还原与过渡金属催化相结合, 从商业可得的试 剂出发, 实现了醛与炔烃的高区域选择性和高对映选择 性还原偶联. 该反应解决了炔一醛不对称还原偶联反应 中长期存在的选择性控制问题. 该反应具有温和的反应 条件及良好的官能团耐受性，为手性烯丙醇骨架的合成 提供了新的思路. 同时, 该研究进一步丰富了过渡金 属一光协同催化的不对称反应.

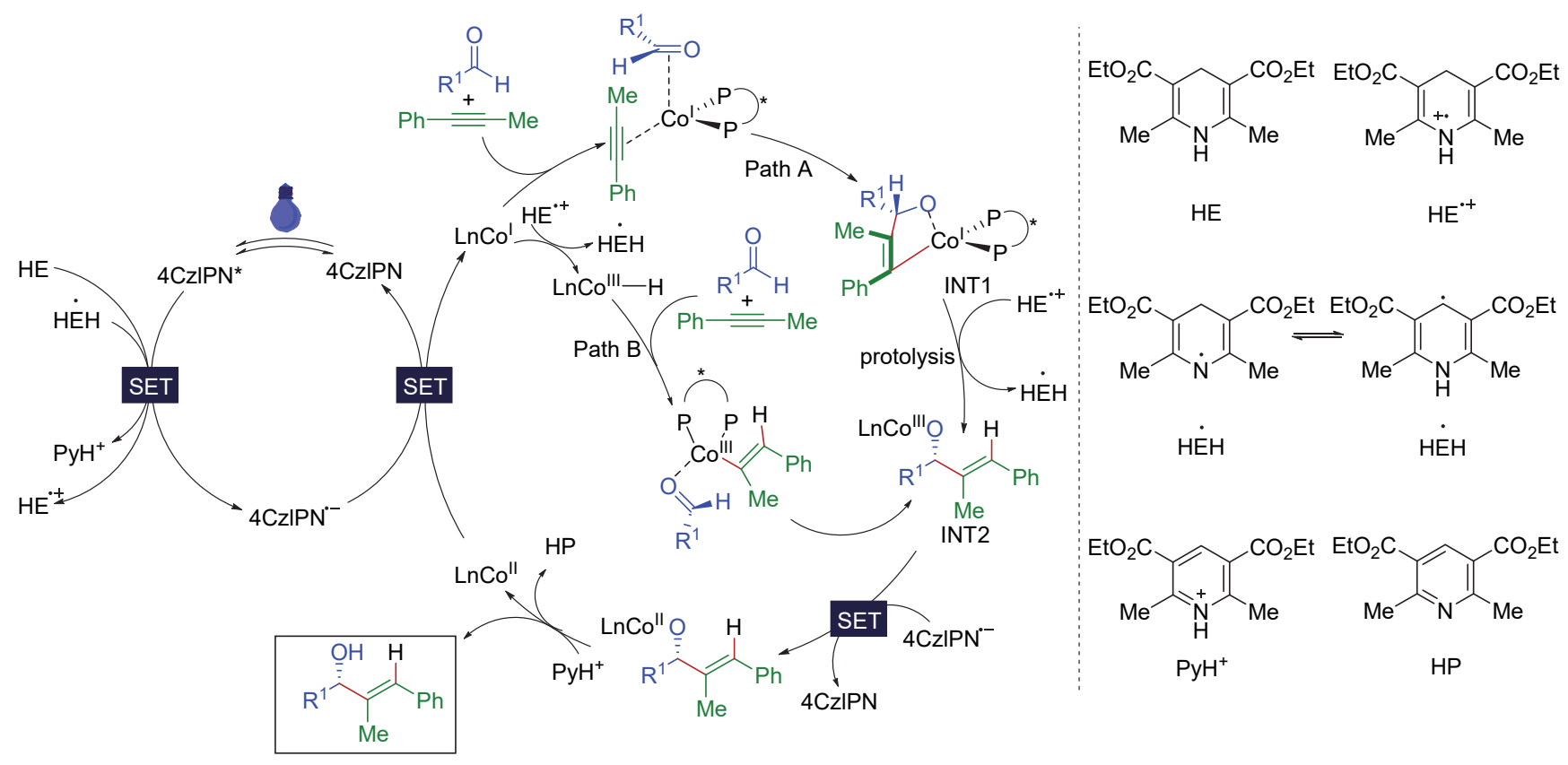

图式 3 可能的反应机理

Scheme 3 Plausible reaction mechanism

\section{References}

[1] Lumbroso, A.; Cooke, M. L.; Breit, B. Angew. Chem., Int. Ed. 2013, 52, 1890.

[2] Li, H.; Walsh, P. J. J. Am. Chem. Soc. 2004, 126, 6538.

[3] Tomita, D.; Wada, R.; Kanai, M.; Shibasaki, M. J. Am. Chem. Soc. 2005, 127, 4138.

[4] Huddleston, R. R.; Jang, H.-Y.; Krische, M. J. J. Am. Chem. Soc. 2003, 125, 11488

[5] Standley, E. A.; Tasker, S. Z.; Jensen, K. L.; Jamison, T. F. Acc. Chem. Res. 2015, 48, 1503.
[6] Chaulagain, M. R.; Sormunen, G. J.; Montgomery, J. J. Am. Chem. Soc. 2007, 129, 9568.

[7] Ai, W.; Zhong, R.; Liu, X.; Liu, Q. Chem. Rev. 2019, 119, 2876.

[8] Dai, Z.; Yu, Z.; Bai, Y.; Li, J.; Peng, J. Chin. J. Org. Chem. 2020, 40, 1177 (in Chinese).

(代自男, 余泽浩, 白赢, 厉嘉云, 彭家建, 有机化学, 2020, 40, 1177.)

[9] Li, Y.-L.; Zhang, S.-Q.; Chen, J.; Xia, J.-B. J. Am. Chem. Soc. 2021, 143, 7306.

[10] Li, Y.-L.; Li, W.-D.; Gu, Z.-Y.; Chen, J.; Xia, J.-B. ACS Catal. 2020, 10, 1528. 